\title{
Interface and Safety Properties of Phosphorus-based Negative Electrodes in Li-ion Batteries
}

C. Marino*, M. El Kazzi, E. J. Berg, M. He, and C. Villevieille*

Paul Scherrer Institute, Electrochemistry Laboratory, CH-5232 Villigen PSI, Switzerland

Email: Cyril.marino@psi.ch; Claire.villevieille@psi.ch

Phosphorus is considered as a promising candidate for the replacement of graphite as the active material in Li-ion battery electrodes owing to its six-fold higher theoretical specific charge. Unfortunately, phosphorus-based electrodes suffer from large volume changes upon cycling, leading to poor electrochemical performance. Furthermore, red phosphorus $\left(\mathrm{P}_{\text {red }}\right)$ is known to release phosphine gas $\left(\mathrm{PH}_{3}\right)$ once in contact with water (even at the ppm level), and thus, its safety profile need to be asset. In this context, the electrolyte/electrode interface of a $P_{\text {red }}$ electrode during the $1^{\text {st }}$ lithiation is fully investigated using scanning electron microscopy (SEM), X-ray photoelectron spectroscopy (XPS), and, on-line electrochemical mass spectroscopy (OEMS). The XPS analyses reveal that at potentials higher than $1 \mathrm{~V}$ vs. $\mathrm{Li}^{+} / \mathrm{Li}$, the $\mathrm{P}_{\text {red }}$ starts to react via the outermost surface layer, which is mainly composed of the native oxide, $\mathrm{P}_{2} \mathrm{O}_{5}$ to form $\mathrm{H}_{3} \mathrm{PO}_{4}$. Once this surface oxide is consumed, the $\mathrm{P}_{\text {red }}$ reacts with moisture and the electrolyte, resulting in the re-formation of $\mathrm{H}_{3} \mathrm{PO}_{4}$ and the release of the toxic $\mathrm{PH}_{3}$ as identified by OEMS. At potential lower than $1 \mathrm{~V}$, a solid electrolyte interphase (SEI) develops on the top of $\mathrm{H}_{3} \mathrm{PO}_{4}$ as identified by XPS analyses. This SEI prevents further degradation of the $\mathrm{P}_{\text {red }}$ and inhibits $\mathrm{PH}_{3}$ release. Following the lithiation, the lithiation process takes place generating particles fracture (identified by SEM) and the transformation of $\mathrm{H}_{3} \mathrm{PO}_{4}$ into $\mathrm{Li}_{3} \mathrm{PO}_{4}$ is also notified. Understanding and monitoring the role of the decomposition products and processes within the battery is crucial to further improving battery performance and safety.

\section{Keywords:}

Lithium ion battery, phosphorus electrode, phosphine, solid electrolyte interphase, reaction mechanism 


\section{Introduction}

Among the most important features required for the advancement of Li-ion batteries are low cost, high energy, high power, and excellent safety. Significant effort has been dedicated to the development of novel negative electrode materials with higher energy densities that could potentially replace the graphite used as negative electrodes in commercial batteries. Red phosphorus $\left(\mathrm{P}_{\text {red }}\right)$ offers an attractive theoretical specific charge of $2595 \mathrm{mAh} \cdot \mathrm{g}^{-1}$ when reacting with lithium to form $\mathrm{Li}_{3} \mathrm{P},{ }^{1}$ compared to the $372 \mathrm{mAh} \cdot \mathrm{g}^{-1}$ obtained from $\mathrm{LiC}_{6}{ }^{2}$ However, $\mathrm{P}_{\text {red }}$ suffers from severe volume changes when reacting with $\mathrm{Li}$, which enhances electrolyte decomposition and leads to particle fracturing and electrical disconnection. Furthermore, $\mathrm{P}_{\text {red }}$ is known to have very poor electrical conductivity, and thus, to enhance its potential as a negative electrode candidate, research has focused on embedding it in a conductive carbon matrix..$^{3,4,5}$ Recently, many papers focused on the engineering of the electrode materials based on conversion/alloy reactions. It turns out that the binder as well as the particle size distribution are playing an important role in keeping a relatively stable specific charge along multiple cycles. To date, Na-CMC (sodium carboxymethyl cellulose) and PAA (poly(acrylic acid)) binders are the most commonly used with phosphorus based active materials. They demonstrated very good cycling stability along long-term cycling once coupled to nano-particles ${ }^{6-8}$. However, very good performances were also reported with PVDF (polyvinylidene difluoride) binder despite its early decomposition during cycling. 9,10

Surprisingly, few studies dedicated to the side reactions that can occur at the electrolyte/electrode

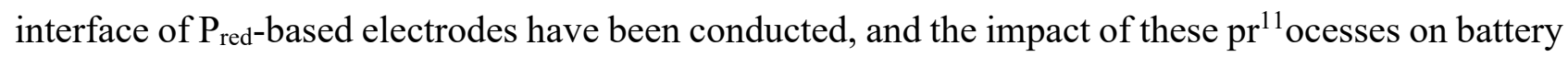
performance and safety are not well understood. For these reasons, elucidating the role of the solid electrolyte interphase (SEI) and its role on the safety battery aspect are crucial for the future integration and development of these materials. It is well known from the literature that $\mathrm{PH}_{3}$ can be generated from $\mathrm{P}_{\text {red }}$ in aqueous system even if this reaction seems to be rate dependent. ${ }^{12,13} \mathrm{The}^{\mathrm{PH}_{3}}$ exposure level considered immediately dangerous to life or health (IDLH) is only ca. $50 \mathrm{ppm}$. The 
U.S. National Institute for Occupational Safety and Health (NIOSH) recommends that the short-term respiratory exposure to phosphine gas should not exceed $1 \mathrm{ppm} .{ }^{14}$ To the best of our knowledge, and

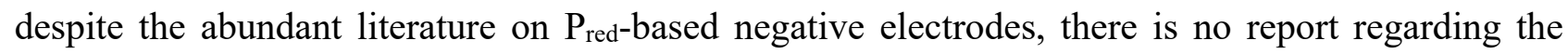
possibility of $\mathrm{PH}_{3}$ release during cycling in presence of organic electrolyte containing few ppm of water, which would be a severe safety issue to consider in the development of $\mathrm{P}_{\text {red-based electrodes. }}$ In this context, we utilized surface characterization techniques scanning electron microscopy (SEM), on-line electrochemical mass spectroscopy (OEMS), and X-ray photoemission spectroscopy (XPS) to probe the electrode/electrolyte interface of P-based electrodes upon the initial lithiation. By this approach, the reactions taking place at the electrolyte/electrode interface were elucidated mechanistically.

\section{Experimental Section}

Electrochemistry. Electrodes were prepared by mixing $80 \mathrm{wt} \% \mathrm{P}_{\text {red }}$ (Sigma-Aldrich), $10 \mathrm{wt} \%$ carbon black (CB, Super C65, Imerys) and $10 \mathrm{wt} \%$ polyvinylidene fluoride (PVDF, HSV-900, Arkema) in $N$-methyl-2-pyrrolidone (NMP, Alfa Aesar). The slurry was cast onto copper foil used as a current collector and dried under vacuum at $80^{\circ} \mathrm{C}$. Electrodes $(13 \mathrm{~mm}$ diameter $)$ were punched and dried under dynamic vacuum at $80^{\circ} \mathrm{C}$ overnight. The active material loading was estimated at ca. $5 \mathrm{mg} \cdot \mathrm{cm}^{-2}$. Where specified, several electrodes (designated as $\mathrm{P}_{\text {powder }}$ electrodes) were prepared without binder by mixing $60 \mathrm{wt} \% \mathrm{P}_{\text {red }}$ and $40 \mathrm{wt} \% \mathrm{CB}$ in a mortar. The mixture was then converted into a pellet by pressing under 3 tons. Electrochemical cells in coin-type cells were assembled in an Ar-filled glove box using a glass fiber separator coupled to a plasticized polypropylene separator (ESPJ137, Lainière de Picardie) and metallic lithium as a counter electrode. A solution of $\mathrm{LiClO}_{4}$ (1 M) dissolved in 1:1 ethylene carbonate (EC) and dimethyl carbonate (DMC) (i.e., LC30) was used as the electrolyte and the water content was measured at $18 \mathrm{ppm}$ by Karl Fisher Titration. Similar results were obtained from the common LP30 electrolyte (1 M LiPF 6 in 1:1 EC:DMC) as can be seen in Supporting Information (Figure S1 and Figure S2). In the case of the measurement performed with $\mathrm{LiPF}_{6}$ salt, the XPS phosphorus signals originate from the salt overlap with the signals of the 
phosphorus from the active material. Such an overlapping of both signals makes the analysis and interpretation of the phosphorus reaction mechanism very challenging if not impossible. Furthermore, the XPS signal of the fluorine of the PVDF is also overlapping the one of the $\mathrm{LiPF}_{6}$ salt. Thus, for the rest of the analysis we will use $\mathrm{LiClO}_{4}$ salt.

The cells were cycled in galvanostatic mode at $25^{\circ} \mathrm{C}$ between $2.0 \mathrm{~V}$ and $5 \mathrm{mV}\left(\mathrm{vs} . \mathrm{Li}^{+} / \mathrm{Li}\right)$ at a $\mathrm{C} / 30$ rate (a full charge or discharge in $30 \mathrm{~h}$ ). For the cells cycled for the SEM and XPS analyses, a potentiostatic step of $8 \mathrm{~h}$ was applied at the end of the desired potential. Throughout the manuscript, the potentials are given compared to the $\mathrm{Li}$ metal reference, i.e., vs. $\mathrm{Li}^{+} / \mathrm{Li}$.

Measurements were monitored with a computer-controlled battery cycling device (CCCC; Astrol Electronic AG, Switzerland). After cycling, the cells were disassembled in an Ar-filled glove box and the electrodes were gently washed with DMC prior to their transfer to the SEM and XPS using a special air-tight transfer chamber.

Scanning electron microscopy (SEM). SEM measurements were performed with a Carl Zeiss Ultra55 scanning electron microscope, using both the secondary electron and InLens modes. The images were taken at an acceleration voltage of $3 \mathrm{kV}$ to ensure that i) we are not damaging the surface (composed of SEI, generally degrading at high acceleration voltage) and, ii) the quality is sufficient enough to avoid too much charging effect.

On-line electrochemical mass spectroscopy (OEMS). The working principle of the OEMS setup and cell has been described elsewhere. ${ }^{15}$ Briefly, the setup comprises a quadrupole mass spectrometer (MS, QMS 200, Pfeiffer Prisma ${ }^{\mathrm{TM}}$, Germany) for partial pressure measurements, a pressure transducer (PS, PAA-33X, Keller Druck AG, Switzerland) for cell pressure, temperature, and internal volume determinations, stainless steel gas pipes and Swagelok fittings $(3 \mathrm{~mm}$ compression tube fittings, Swagelok, OH, US) for OEMS cell attachment, a set of solenoid valves (2-way magnetic valve, Series 99, silver-plated nickel seal, Parker, US), and a scroll pump (nXDS15i, EDWARDS $\mathrm{GmbH}$, Germany) for efficient flushing. The magnetic valves were automatically opened/closed with a solid-state relay module (NI 9485 Measurement System, National Instruments, TX, US) connected 
to a computer with homemade LabVIEW software (NI LabVIEW 2013, National Instruments, TX, US). Linear sweep voltammetry $\left(40 \mu \mathrm{V} \cdot \mathrm{s}^{-1}\right)$ with the $P_{\text {red-based working electrodes in a potential }}$ window of $5 \mathrm{mV}$ to $-3.0 \mathrm{~V}$ vs. $\mathrm{Li}^{+} / \mathrm{Li}$ was performed against a $\mathrm{Li}$ metal counter electrode at room temperature using the CCCC device. During the measurements, any gases arising from the electrode/electrolyte interface into the headspace of the OEMS cell were pumped off to the mass spectrometer for analysis. The time delay between the formation of the gases at the electrode surface and their detection at the mass spectrometer was estimated at a maximum of $10 \mathrm{~min}$. The mass signals were recorded as a function of time and cell voltage. Changes in the ion current intensities were monitored by selectively scanning the mass-per-electron signals at $m / z=2\left(\mathrm{H}_{2}\right), 28\left(\mathrm{C}_{2} \mathrm{H}_{4}\right), 34\left(\mathrm{PH}_{3}\right)$, $40(\mathrm{Ar})$, and $44\left(\mathrm{CO}_{2}\right)$. The gas evolution rates of $\mathrm{H}_{2}, \mathrm{C}_{2} \mathrm{H}_{4}$, and $\mathrm{CO}_{2}$ were accounted for by calibration of the mass spectrometer with gas standards of known concentration. No gas standard was available for $\mathrm{PH}_{3}$, which was accounted for semi-quantitatively by employing the same sensitivity factor as for $\mathrm{O}_{2}$. This rough estimation is reasonable considering that most sensitivity factors are found in the same order of magnitude. ${ }^{16}$

X-ray photoelectron spectroscopy (XPS). XPS measurements were carried out with a VG ESCALAB 220iXL (Thermo Fisher Scientific) spectrometer using focused monochromatized Al K $\alpha$ radiation $(h v=1486.6 \mathrm{eV})$. The spectrometer was calibrated using the $\mathrm{Ag} 3 d_{5 / 2}$ peak at a binding energy of $368.3 \mathrm{eV}$. The X-ray spot size was about $500 \mu \mathrm{m}^{2}$ (power: $150 \mathrm{~W}$ ) and the pressure in the analysis chamber was about $2 \times 10^{-9}$ mbar. The spectra were recorded in the constant analyzer energy mode at a pass energy of $30 \mathrm{eV}$ in steps of $50 \mathrm{meV}$ with a dwell time of $5 \mathrm{~ms}$. Control spectra were recorded at the beginning and end of each experiment to certify that the sample did not evolve with time or suffer beam damage. The BE scale was calibrated with respect to the $\mathrm{C} 1 s$ component of the $\mathrm{CB}(\mathrm{C}-$ $\mathrm{C}$ bonds), set at $284.4 \mathrm{eV}$. Peak deconvolution was performed by applying the sum of the Gaussian (70\%) and Lorentzian (30\%) line shapes after Shirley-type background subtraction. Deconvolutions of the $\mathrm{P} 2 p$ peaks were realized by fixing their spin-orbit splitting and branching ratio to $0.87 \mathrm{eV}$ and 0.5 , respectively. In the study, only the $\mathrm{P} 2 p_{3 / 2}$ component is described for the spectral analysis. No 
charge compensation was used for the XPS measurements on $\mathrm{P}_{\text {red }}$ electrodes mixed with carbon and binder. However, for the $\mathrm{P}_{\text {red }}$ raw pristine powder, a flood gun was used to compensate the charge due to its very poor electrical conductivity.

\section{Results}

The galvanostatic curve for the $1^{\text {st }}$ cycle of the P-based electrode is displayed in Figure 1. The OCV starts at $3.1 \mathrm{~V}$ and decreases almost instantly to reach a short potential plateau at ca. $0.85 \mathrm{~V}$, attributed to SEI formation (region I). Then, the potential drops quickly to $0.35 \mathrm{~V}$, at which the reaction starts, with the formation of the first intermediate LiP phase as indicated in the Material projects website ${ }^{17}$, 18. The formation of the $\mathrm{Li}_{3} \mathrm{P}$ phase is characterized by the slow decrease of the potential to $5 \mathrm{mV}$, as has been described in the literature (region II). ${ }^{4}$ As expected from its low conductivity, the theoretical specific charge $\left(2595 \mathrm{mAh} \cdot \mathrm{g}^{-1}\right)$ of $\mathrm{P}_{\text {red }}$ is not reached $\left(1946 \mathrm{mAh} \cdot \mathrm{g}^{-1}\right)$, despite the use of a potentiostatic step of $2 \mathrm{~h}$ at $5 \mathrm{mV}$ and the addition of the carbon additive. Consequently, part of the P-based electrode does not react properly, because either the particles are disconnected from the carbon network, or only their surfaces react while the phosphorus core remains undisturbed (due to the low conductivity, the kinetics is extremely slow). As expected from the poor lithiation, the delithiation process is extremely rapid (region III) with a coulombic efficiency of ca. $6.5 \%{ }^{4}$

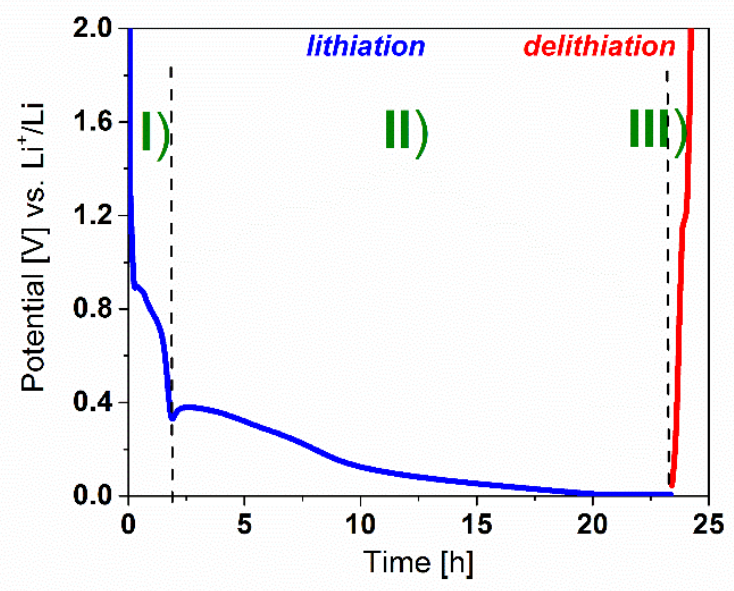

Figure 1. Galvanostatic profile of the $1^{\text {st }}$ cycle of the $\mathrm{P}_{\text {red-based electrode. }}$ 
Figure 2 shows the morphological changes of the electrode with cycling. In the pristine electrode (Figure $2 \mathrm{a} \& 2 \mathrm{~b}$ ), micron-sized phosphorous particles are embedded in the CB/PVDF matrix. However, as lithiation proceeds, the particle morphology markedly changes; at $0.95 \mathrm{~V}$ (Figure 2c \& 2d), the surface appears smoother and/or covered by a polymer layer (most probable the organic SEI layer). Upon reaching $0.65 \mathrm{~V}$ (Figure 2e \& 2f), several filaments appear in the SEM images, which may be attributed to the SEI due to their charging effect and their decomposition under microscopy beam (melting observed in the images after several seconds of exposure). For all the samples cycled below $0.65 \mathrm{~V}$, a charging effect indicating the formation of a thick polymeric insulating SEI layer is observed. As the lithiation proceeds, significant fractures in the phosphorous particles can be noted at $150 \mathrm{mV}$ (see Supporting Information, Figure S3), indicating a substantial volume change due to the reaction Li-P (Figure $2 \mathrm{~g} \& 2 \mathrm{~h}$ ). At full lithiation $(5 \mathrm{mV}$, Figure $2 \mathrm{i} \& 2 \mathrm{j})$, the particles are pulverized due to the large volume change (full lithiation to $\mathrm{Li}_{3} \mathrm{P}$ causes a volume change of $216 \%$ ), and only particles smaller than $2 \mu \mathrm{m}$ are visible. 

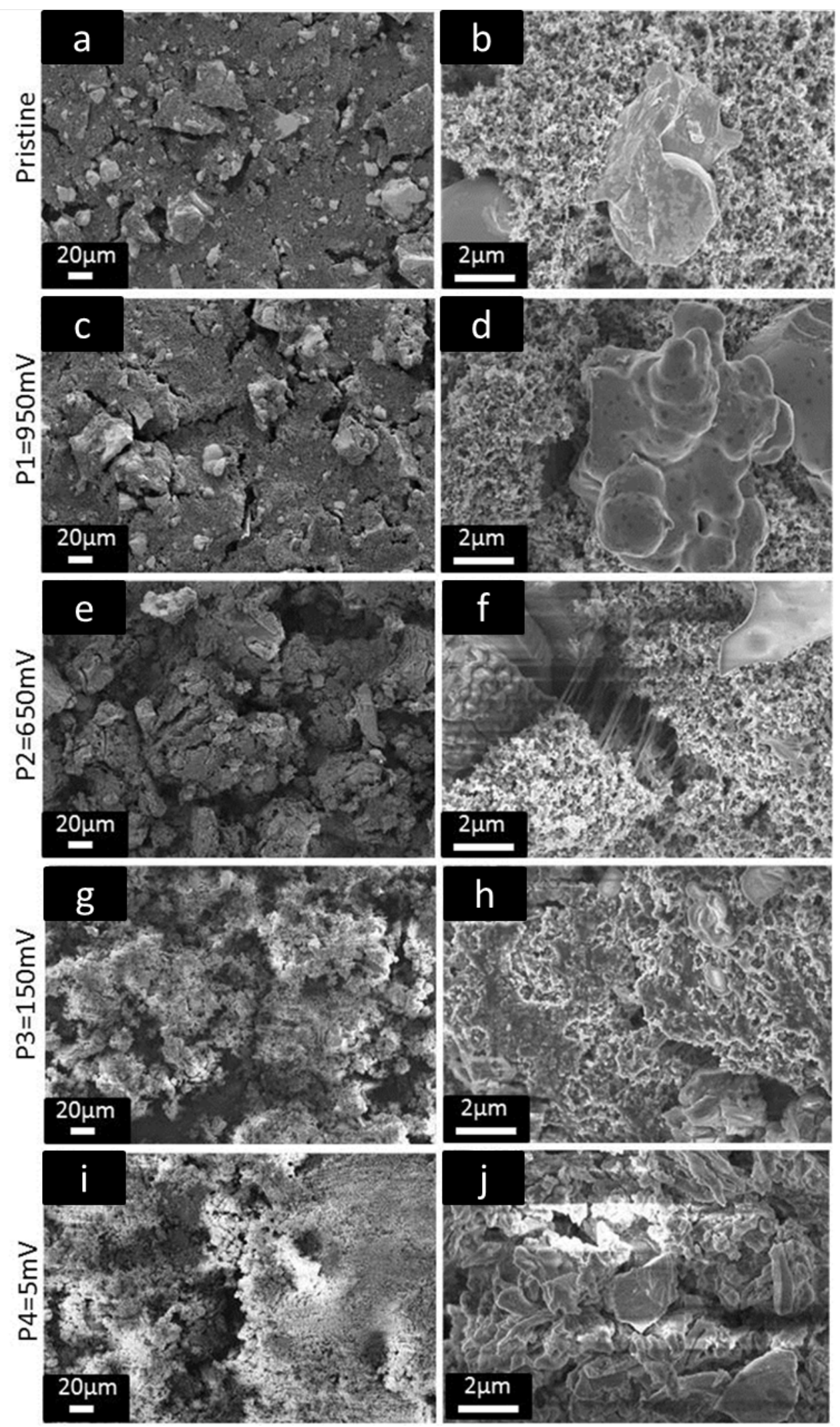

Figure 2. SEM images (two magnifications) of the pristine and post-mortem cycled $P_{\text {red }}$ electrodes: a,b) pristine; and after cycling at c,d) $0.95 \mathrm{~V}$; e,f) $0.65 \mathrm{~V}$; g,h) $150 \mathrm{mV}$; and i,j) $5 \mathrm{mV}$.

The OEMS analysis of the P-based electrode is displayed in Figure 3. The $\mathrm{P}_{\text {red-based electrode cycled }}$ using linear sweep voltammetry, displays cycling behavior similar to that reported in Figure 1, with 
two main cathodic peaks near 0.8 and $0.35 \mathrm{~V}$. A signal for $\mathrm{H}_{2}(m / z=2)$ appears at an early cycling stage (i.e., $2.2 \mathrm{~V}$ ), which is attributed to the reduction of protons in the electrolyte. This signal evolves constantly during the discharge, with three separate maxima at 1.8, 0.9, and $0.4 \mathrm{~V}$. Surprisingly, $\mathrm{PH}_{3}$

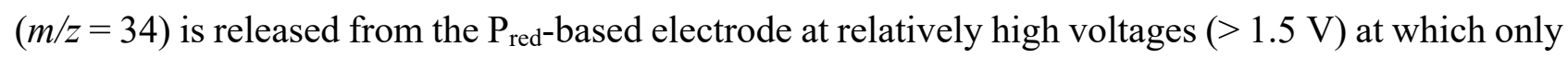
surface reactions can occur, since the Li-P reaction starts below $1 \mathrm{~V}$. The maximum for $\mathrm{PH}_{3}$ evolution is reached at ca. $1.6 \mathrm{~V}$ (still far removed from the $\mathrm{Li} / \mathrm{P}$ reaction potential); then, the evolution rate decreases slightly, reaching a second maximum at ca. $1.1 \mathrm{~V}$. However, below $1.1 \mathrm{~V}$, after the onsets of the Li-P reaction and SEI formation, no additional $\mathrm{PH}_{3}$ is detected. Unfortunately, these results

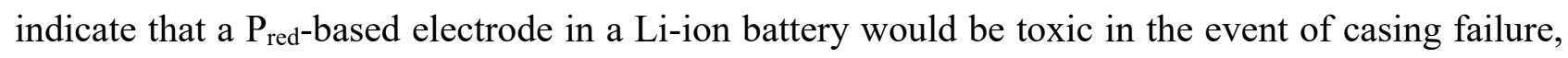
and its use as replacement for graphite in Li-ion batteries should, accordingly, be of concern. At ca. $1 \mathrm{~V}$, as would be expected from SEI formation, ethylene gas $(m / z=28)$, a well-known decomposition product of ethylene carbonate (EC), is formed. ${ }^{19}$ After full lithiation, a second small release of $\mathrm{C}_{2} \mathrm{H}_{4}$ is observed, which can be attributed to the development of an SEI on the fractured particle surfaces. Indeed, at the end of lithiation, the largest volume change in the particles (largest amount of $\mathrm{Li}_{3} \mathrm{P}$ ) is observed. As discussed for Figure 1, the theoretical capacity of the $\mathrm{P}_{\text {red-based electrodes is clearly not }}$ attained; thus, a core-shell process, in which only the surfaces of the P particles react and the cores remain as $\mathrm{P}$, is suggested to occur. When the large particles start to fracture, they release fresh $\mathrm{P}$ based surfaces (Figure $2 \mathrm{~g}-\mathrm{j}$ ), and the opportunity for additional SEI formation.

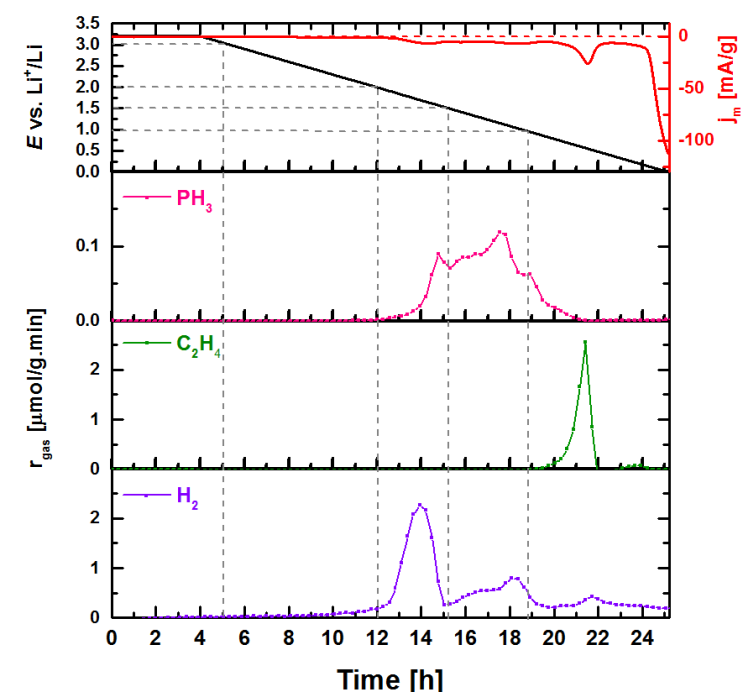


Figure 3. Potential (black), current response (red), and $\mathrm{C}_{2} \mathrm{H}_{4}$ (green), $\mathrm{H}_{2}$ (violet), as well as $\mathrm{PH}_{3}$ (pink) gas evolution profiles for OEMS cells containing $\mathrm{P}_{\text {red }}$ based electrodes.

The OEMS measurements show two distinguishable regions, one higher than $1 \mathrm{~V}$ that is attributed to surface reactions with the release of $\mathrm{PH}_{3}$, and the other lower than $1 \mathrm{~V}$ that is attributed to SEI formation and the Li-P reaction. To understand the origins of these different, mostly surface, reactions, we followed the first lithiation by XPS post-mortem analyses.

The XPS measurements of the C $1 s$ and $\mathrm{P} 2 p$ core levels acquired on the pristine electrode and at the open circuit potential (OCP) are displayed in Figure 4 whereas the F 1s and $\mathrm{Cl} 2 \mathrm{p}$ core spectra are reported in the Supporting Information, Figure S4 and S5. Three main components are visible in the C $1 s$ core level at 284.5, 286.8, and $291.2 \mathrm{eV}$, ascribed to $\mathrm{CB}(\mathrm{C}-\mathrm{C}), \mathrm{CH}_{2}$, and $\mathrm{CF}_{2}$ from the PVDF, respectively. ${ }^{19,20}$ Smaller contributions are attributed as follows: 285.6, 287, and $288.6 \mathrm{eV}$ associated with $\mathrm{C}-\mathrm{H}$ (hydrocarbon), $\mathrm{C}=\mathrm{O}$, and $\mathrm{O}-\mathrm{C}=\mathrm{O}$ species, respectively. ${ }^{21}$

At the OCP, the $\mathrm{C} 1 \mathrm{~s}$ core level spectrum shows slight changes compared to the pristine sample, a small increase of the hydrocarbon component is observed, which is believed to be associated to adsorbed species from the DMC and EC. A slight shift to higher BE was also observed for the two PVDF components $\mathrm{CF}_{2}$ and $\mathrm{CH}_{2}$ respect to the carbon black components, which is probably linked to the spontaneous decomposition of the PVDF binder caused by the electrolyte, leading to LiF peak (Figure S4, Supporting Information). The $\mathrm{Cl} 2 p$ and $\mathrm{O} 1 s$ core spectra recorded at OCP can be found in Supporting Information (Figure S5).

The spectrum of the $\mathrm{P} 2 p$ core level of the pristine electrode presents three main components ( $\left.\mathrm{P} 2 p_{3 / 2}\right)$ at $129.5,130.2$, and $134.6 \mathrm{eV}$. The component at $130.2 \mathrm{eV}$ is attributed to $\mathrm{P}-\mathrm{C}$ species, ${ }^{5,22,23}$ whereas the one at $129.5 \mathrm{eV}$ is related to $\mathrm{P}_{\text {red }}$ with a zero-oxidation state $\left(\mathrm{P}^{0}\right)$. To ensure the proper assignment of the phosphorus components, we compared $\mathrm{P} 2 p$ core level spectra acquired on $\mathrm{P}_{\text {powder }}$ (with and without the addition of carbon) to that for the standard electrode, $\mathrm{P}_{\mathrm{red}} / \mathrm{C} / \mathrm{PVDF}$. The results, displayed in the supplementary information (see Figure S6, Supporting Information), show that $\mathrm{P}-\mathrm{C}$ and $\mathrm{P}_{2} \mathrm{O}_{5}$ 
components evolve strongly in the presence of the conductive carbon. This observation highlights the reactivity of the phosphorus surface with carbon and traces of moisture. The $\mathrm{P}-\mathrm{C}$ species are also visible in the $\mathrm{C} 1 s$ core level spectrum, as a component at $283.5 \mathrm{eV}$. The third component in the $\mathrm{P} 2 p$ core level spectrum at $134.6 \mathrm{eV}$ is related to the native phosphorous oxide (the pentoxide, $\mathrm{P}_{4} \mathrm{O}_{10}\left(\mathrm{P}^{+5}\right)$ ) that develops at the surface of the $\mathrm{P}_{\text {red. }}{ }^{3,24} \mathrm{An}$ additional minor contribution at $131.7 \mathrm{eV}$ is assigned to $\mathrm{P}_{4} \mathrm{O}_{2 .}{ }^{25}$ Unlike the $\mathrm{C} 1 s$ core level, a shift of the pentoxide component to lower binding energy (BE), from 134.6 to $133.8 \mathrm{eV}$, is observed (Figure 4-b) at the OCP, due to the spontaneous reaction that occurs between the native $\mathrm{P}_{2} \mathrm{O}_{5}$ and the electrolyte. Similar behavior is noticed in the $\mathrm{P} 2 p$ core level of the soaked $\mathrm{P}_{\text {powder }}$-electrode, confirming that a chemical reaction occurs with the electrolyte (see Figure S7, Supporting Information). As $\mathrm{P}_{2} \mathrm{O}_{5}$ is known to be a drying agent for solvents, we believe it reacts with the traces of water (ca. $20 \mathrm{ppm}$ ) to form $\mathrm{H}_{3} \mathrm{PO}_{4}$ (Equation 1). Therefore, the component at $133.8 \mathrm{eV}$ is assigned to $\mathrm{H}_{3-x} \mathrm{PO}_{4}{ }^{3-x}$, which will be further discussed below. ${ }^{26}$

$$
\mathrm{P}_{2} \mathrm{O}_{5}+3 \mathrm{H}_{2} \mathrm{O} \rightarrow 2 \mathrm{H}_{3} \mathrm{PO}_{4}
$$
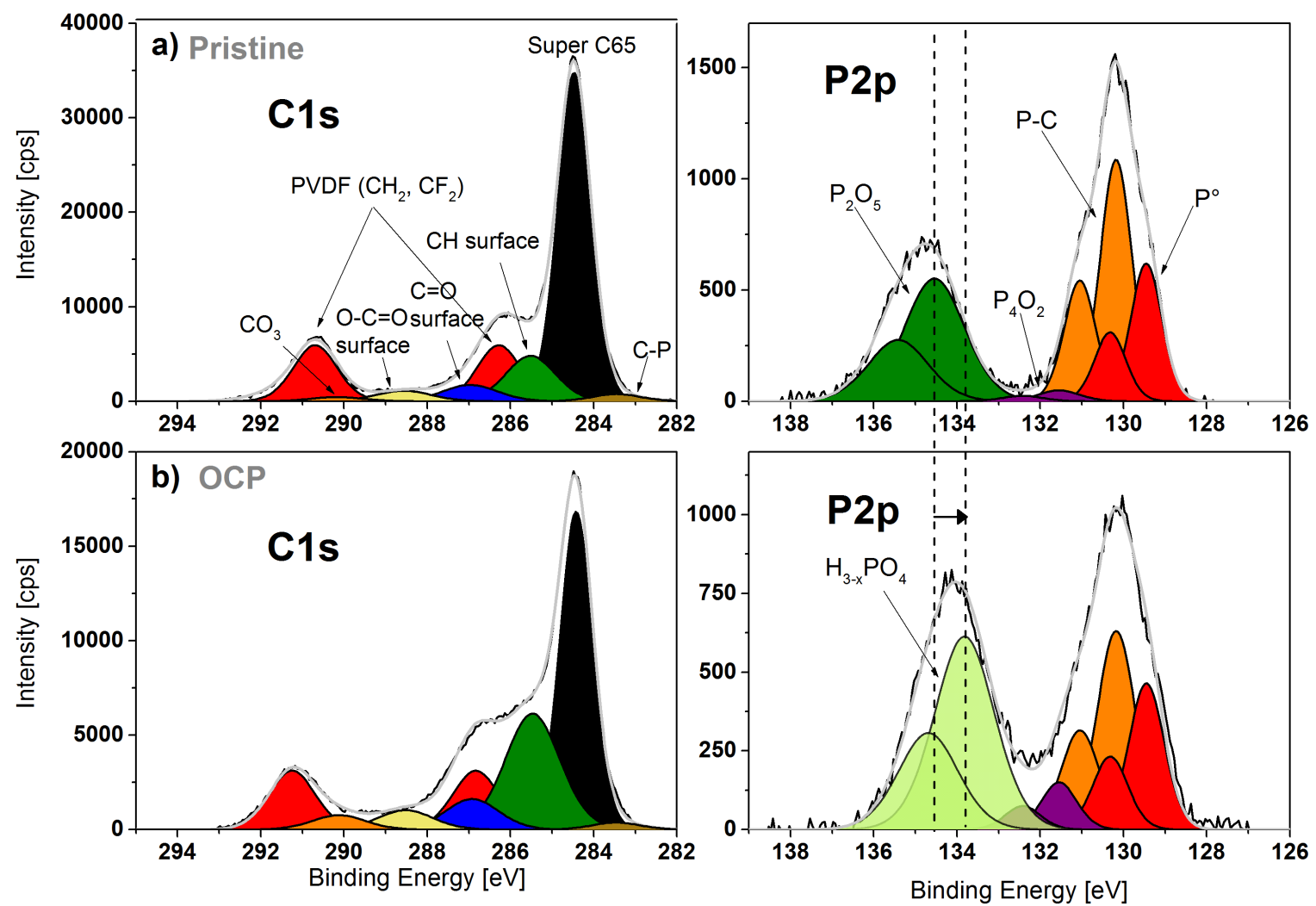
Figure 4. C $1 s$ and P $2 p$ XPS core level spectra acquired on a) pristine $\mathrm{P}_{\text {red }}$ electrode and b) electrode at the OCP.

The electrode/electrolyte interactions were further investigated by measuring different key potentials from $2.0 \mathrm{~V}$ to $5 \mathrm{mV}$. The spectra for the $\mathrm{C} 1 s$ and $\mathrm{P} 2 p$ core levels are presented in Figure 5, while the one of F1s core level and C12p core level are displayed in the Figure S8 and S9. At 2 V (Figure 5-a), the $\mathrm{H}_{3} \mathrm{PO}_{4}$ component in the $\mathrm{P} 2 p$ spectrum slightly shifts to higher $\mathrm{BE}$ at $134.2 \mathrm{eV}$, whereas no change appears in the $\mathrm{C} 1 s$ core level. Due to its strongly acidic nature, $\mathrm{H}_{3} \mathrm{PO}_{4}$ is unstable toward residual water and other ions in the electrolyte, leading to proton-deficient phosphoric acid species $\left(\mathrm{H}_{3-x} \mathrm{PO}_{4}{ }^{3-x}\right)$. In the literature, Horowitz et al. ${ }^{27}$ showed that the addition of one proton to the $\mathrm{PO}_{4}{ }^{3-}$ ion induced a $1 \mathrm{eV}$ shift to higher BE. Therefore, the loss of a small number of protons should result in a shift to lower BE. This assumption is further confirmed by the oscillation of the BE position of the $\mathrm{H}_{3} \mathrm{PO}_{4}$ component between 134.3 and $134.6 \mathrm{eV}$ in the $\mathrm{P} 2 p$ core levels recorded at different potentials (Figure 5-b-g). Moreover, by comparing the P $2 p$ core level acquired at $2.0 \mathrm{~V}$ (Figure 5-a) to the one recorded at the OCP (Figure 4-b), increasing intensities of the $\mathrm{P}-\mathrm{C} / \mathrm{P}^{0}$ components can be observed, revealing that the $\mathrm{H}_{3} \mathrm{PO}_{4}$ layer is thinner (i.e., it has undergone slight dissolution as it is a strong acid, thus dissolves directly in the electrolyte) at $2 \mathrm{~V}$. According to the $\mathrm{OEMS}$ data, $\mathrm{PH}_{3}$ gas begins to evolve at a similar potential, and the changes seen in the core level could reflect the beginning of this reaction process. At $1.5 \mathrm{~V}$, the $\mathrm{C} 1 \mathrm{~s}$ core level spectrum is starting to show some signs of the SEI formation such as $\mathrm{CO}_{3}$ and $\mathrm{CO}$ peak, directly linked to SEI carbonate products. The P $2 p$ core level spectrum (Figure 5-b) reveals a strong increase in the $\mathrm{H}_{3} \mathrm{PO}_{4}$ component as well as decreases in the $\mathrm{P}^{0}$ and $\mathrm{C}-\mathrm{P}$ components. These phenomena are interpreted as an increase in the thickness of the $\mathrm{H}_{3} \mathrm{PO}_{4}$ "layer" at the outermost surface of the phosphorus particles, which could be caused by an electrochemical reaction inside the cell (Equation 2) followed by a chemical reaction (Equation 3).

$$
\begin{aligned}
& \mathrm{H}_{3} \mathrm{PO}_{4}+5 \mathrm{H}^{+}+5 \mathrm{e}^{-} \rightarrow \mathrm{P}^{0}+4 \mathrm{H}_{2} \mathrm{O} \\
& 1 / 2 \mathrm{P}_{4}+4 \mathrm{H}_{2} \mathrm{O} \rightarrow \mathrm{PH}_{3}+\mathrm{H}_{3} \mathrm{PO}_{4}+\mathrm{H}_{2}
\end{aligned}
$$


Equation 2 describes the reduction of $\mathrm{H}_{3} \mathrm{PO}_{4}$ into $\mathrm{P}^{0}$, which is theoretically expected at ca. $2.6 \mathrm{~V} \cdot{ }^{28} \mathrm{~A}$ similar mechanism was previously proposed by Vogel et al. ${ }^{29}$ in a highly concentrated $\mathrm{H}_{3} \mathrm{PO}_{4}$ electrolyte, where $\mathrm{H}_{3} \mathrm{PO}_{4}$ was reduced on the surface of platinum to form Pt-P bonds. In this case, we believe that the phosphorus reacts with itself, generating "P-P" bonds. Regarding the shift in the reaction potential, it is likely related to the poor conductivity of the phosphorus particles: as they are not all homogeneously coated with carbon, it may be that the higher resistance inside the cell results in a higher polarization.

The chemical reaction given by Equation 3 consists of the re-oxidization of $\mathrm{P}^{0}$ to form $\mathrm{H}_{3} \mathrm{PO}_{4}, \mathrm{PH}_{3}$, and $\mathrm{H}_{2}$. Indeed, the newly formed $\mathrm{P}-\mathrm{P}$ species will be directly exposed to the $\mathrm{H}_{2} \mathrm{O}$ generated through the electrochemical reaction given in Equation 2 and instantaneously consumed. Therefore, a cyclic process is generated between the two reactions (Equation 1 and 2).

In the $1.5-0.6 \mathrm{~V}$ potential range (Figure 5-b-e), the $\mathrm{C} 1 s$ peaks show a continuous decrease in the $\mathrm{CB}$ (C-C) component. Increases are observed in the four components located at $286.1(\mathrm{C}-\mathrm{H}), 288(\mathrm{C}-\mathrm{O})$, $290(\mathrm{O}-\mathrm{C}=\mathrm{O})$, and $291.6 \mathrm{eV}$ (carbonate/dicarbonate species), ${ }^{[20]}$ belonging to the SEI layer. To achieve reliable deconvolution of the SEI components, PVDF-free $\mathrm{P}_{\text {red }}$ electrodes were also analyzed (Figure S10, Supporting Information). All the contributions are shifted to higher BE by about $1 \mathrm{eV}$ compared to the literature, ${ }^{30}$ which is most probably related to a local charging effect ${ }^{31}$ often observed with the decomposition of EC and DMC. ${ }^{20}$

From 1 to $0.6 \mathrm{~V}$ (Figure $5 \mathrm{c}-\mathrm{e}$ ), the absolute intensity of the $\mathrm{H}_{3} \mathrm{PO}_{4}$ component progressively decreases, indicating that this component starts to be covered by an additional layer, i.e., the SEI that grows on the surface of the phosphorus particles. These results are in accordance with the OEMS data in which the formation of ethylene gas due the decomposition of EC was observed in the same potential range (Figure 3). Additionally, we can noticed the decomposition of the PVDF binder occurring mostly below $1 \mathrm{~V}$ as seeing with the presence of $\mathrm{LiF}$ component detected at $\sim 686.5 \mathrm{eV}$ 
(Supporting Information, Figure S8). The same observation can be drawn for the electrolyte salt $\mathrm{LiClO}_{4}$ where $\mathrm{LiCl}$ contribution appears below $1 \mathrm{~V}$ (Supporting Information, Figure S9).

With continued lithiation between 0.6 and $0.4 \mathrm{~V}$ (Figure 5e-f), the SEI does not appear to significantly evolve, as confirmed by the unchanged intensity of the $\mathrm{CB}(\mathrm{C}-\mathrm{C})$ component. At $0.4 \mathrm{~V}$, slight increases in the $\mathrm{P} 2 p$ core levels of the $\mathrm{P}^{0}$ and $\mathrm{C}-\mathrm{P}$ components are observed (Figure $5 \mathrm{f}$ ). Such behavior is explained by the presence of particle fractures caused by the Li-P reaction, as seen in the SEM images (Figure 2-i-j).

At $5 \mathrm{mV}$ (i.e., full lithiation) (Figure 5g), the SEI reaches its maximum thickness, since the CB (CC) signal is in the noise level. For the $\mathrm{P} 2 p$ core level, the increases in the $\mathrm{P}^{0}$ and $\mathrm{C}-\mathrm{P}$ components become even more pronounced (Figure 5g). By deconvoluting the peak, we are able to detect the presence of two $\mathrm{Li}_{x} \mathrm{P}$ components located at 126.6 and $128.6 \mathrm{eV}$ (most likely, $\mathrm{LiP}$ and $\mathrm{Li}_{3} \mathrm{P}$, respectively), and a lithiated $\mathrm{H}_{3} \mathrm{PO}_{4}$ component located at $132.7 \mathrm{eV}$, which is associated with $\mathrm{Li}_{3} \mathrm{PO}_{4}$. The presence of $\mathrm{Li}_{3} \mathrm{PO}_{4}$ is the result of the ionic exchange between protons and $\mathrm{Li}$ ions, and therefore, protons in the electrolyte would be expected, explaining the evolution of $\mathrm{H}_{2}$ at the end of the lithiation. However, we cannot fully exclude the participation of the formed $\mathrm{PH}_{3}$ in the phenomena observed at the end of discharge. ${ }^{32,33,34}$ 

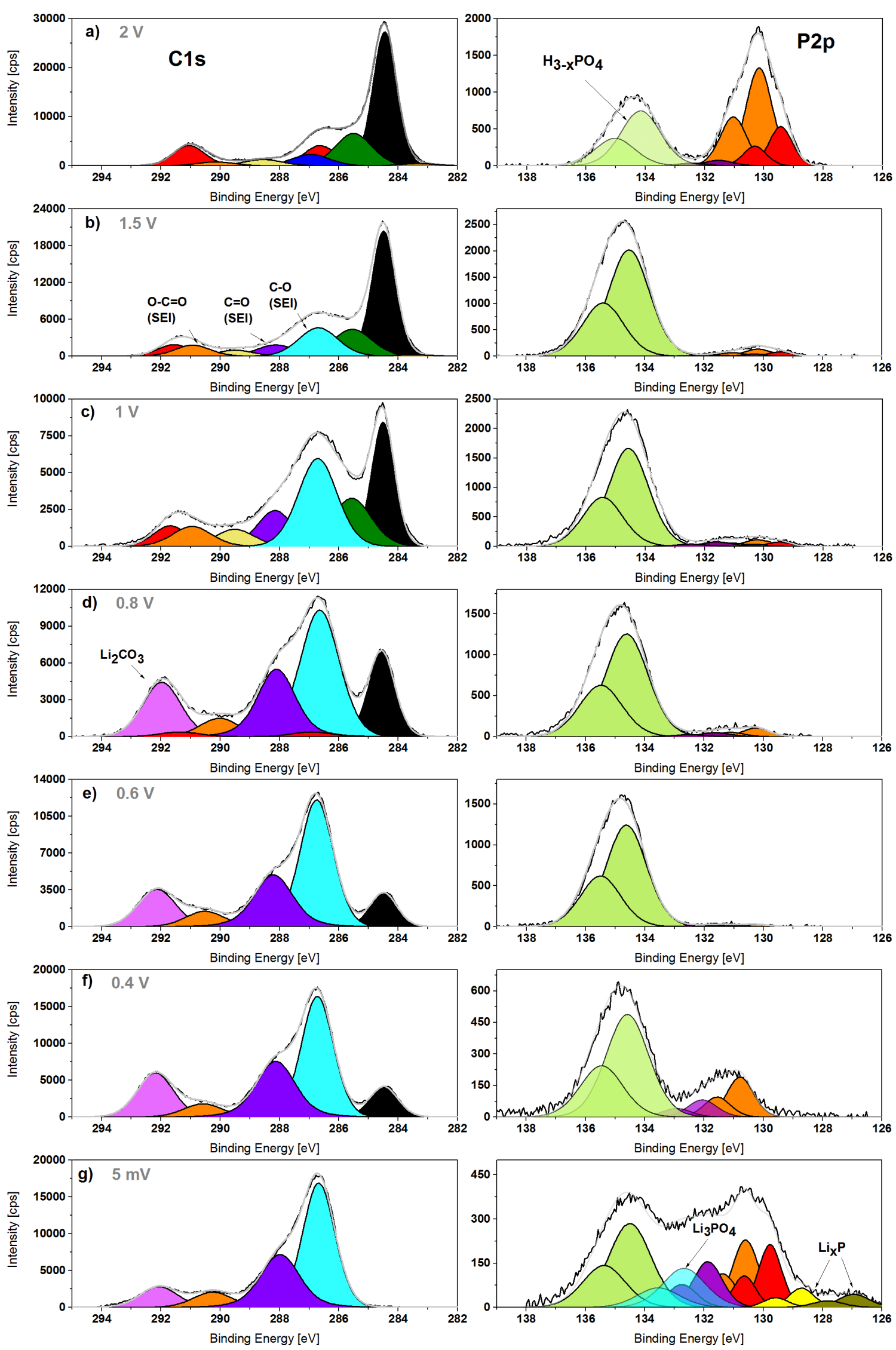

Figure 5. Spectra of the $\mathrm{C} 1 s$ and P $2 p$ XPS core levels acquired on Pred electrodes cycled at a) $2.0 \mathrm{~V}$, b) $1.5 \mathrm{~V}$, c) $1.0 \mathrm{~V}$, d) $0.8 \mathrm{~V}$, e) $0.6 \mathrm{~V}$, f) $0.4 \mathrm{~V}$ and, g) $5 \mathrm{mV}$. 


\section{Discussion}

Based on the foregoing results, we can mechanistically elucidate the reactions that occur during the

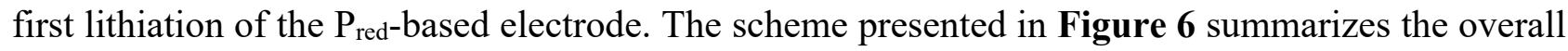
mechanism, which is subdivided into several steps. Based on the detailed XPS analyses, we identified that in the first step (Step 1), $\mathrm{P}_{2} \mathrm{O}_{5}$ reacts chemically with traces of water in the electrolyte, leading to the formation of $\mathrm{H}_{3} \mathrm{PO}_{4}$. The second step (Step 2), with an onset at ca. $3 \mathrm{~V}$, consists of the slight dissolution of $\mathrm{H}_{3} \mathrm{PO}_{4}$ in the electrolyte, which could be facilitated by the presence of residual water. From ca. 2 to $0.6 \mathrm{~V}$ (Step 3), the reduction of $\mathrm{H}_{3} \mathrm{PO}_{4}$ occurs at the outermost surface of the $\mathrm{P}_{\text {red }}$ particles, leading to the formation of reduced phosphorus $\mathrm{P}^{0}$ (Step 3). The freshly formed $\mathrm{P}^{0}$ specie, which is in direct contact with the traces of water generated by the reduction of $\mathrm{H}_{3} \mathrm{PO}_{4}$, will react instantaneously to produce $\mathrm{PH}_{3}, \mathrm{H}_{2}$, and $\mathrm{H}_{3} \mathrm{PO}_{4}$. Because $\mathrm{H}_{3} \mathrm{PO}_{4}$ is regenerated, the reactions are cyclical and the $\mathrm{P}_{\text {red-based electrode continues to decompose. }}$

The formation of the SEI (Step 4) is the key to buffering the decomposition of the $\mathrm{P}_{\text {red-based electrode. }}$ At $0.6 \mathrm{~V}$, we can correlate the release of ethylene (by OEMS) with SEI formation (by XPS) and the binder decomposition, leading to the inhibition of $\mathrm{PH}_{3}$ gas evolution. The surface analyses (XPS combined to SEM) demonstrate that an SEI layer thickness in the range of 4-5 $\mathrm{nm}$ is sufficient to chemically passivate the phosphorus particles and indirectly stop $\mathrm{PH}_{3}$ production. Due to the low electronic conductivity of the SEI, the reduction of $\mathrm{H}_{3} \mathrm{PO}_{4}$ is probably prevented, and then, $\mathrm{PH}_{3}$ cannot be released.

Below $0.4 \mathrm{~V}$, the $\mathrm{P}_{\text {red }}$ particles begin to fracture due to the reaction with Li (SEM analyses); this is correlated with a slight increase in the $\mathrm{P}^{0}$ and $\mathrm{C}-\mathrm{P}$ components, despite the thick SEI layer. Such behavior is possible due to the crack formation in the phosphorus particles and the emergence of fresh surface area that is not yet covered by the SEI due to the insulating nature of $\mathrm{P}_{\text {red. }}$.

Our work evidences a severe safety issue with the formation of toxic $\mathrm{PH}_{3}$ that must be considered, especially if nanoparticles with high surface area in contact with the electrolyte are to be used as anode for Li-ion batteries. For the micrometer-sized $\mathrm{P}_{\text {red }}$ active material aggregates of low surface 
area employed in our electrodes about $1.1 \mathrm{mg} \mathrm{PH}_{3}$ per $\mathrm{g}$ of phosphorus is estimated to be formed on the first discharge, which could be a potential safety hazard if large-scale cells with several hundred grams of phosphorus suffer from gas leakage.

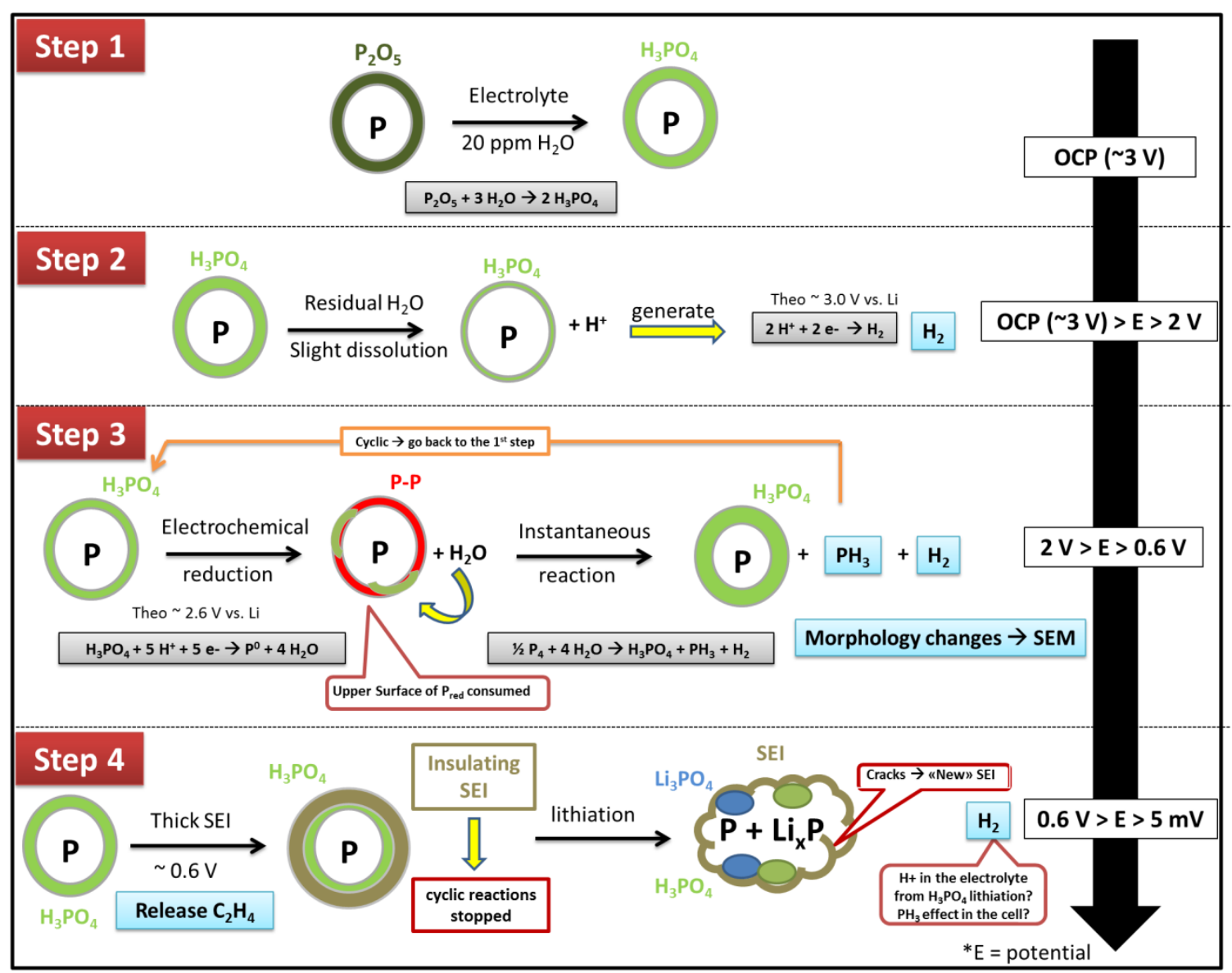

Figure 6. Mechanistic scheme for the reactions occurring at the electrode/electrolyte interface on the $\mathrm{P}_{\text {red }}$-based electrode during the first lithiation.

\section{Conclusion}

By combining three complementary surface characterization techniques (SEM, OEMS, and XPS), we

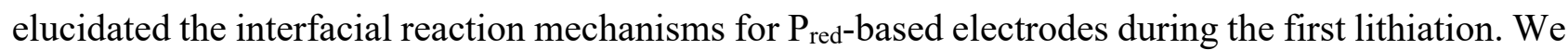
observed three main phenomena: i) the release of phosphine gas $\left(\mathrm{PH}_{3}\right)$ caused by multiple surface reactions; ii) electrolyte reduction; and iii) surface layer passivation (i.e., the formation of an SEI). We demonstrated that the native surface layer composed of $\mathrm{P}_{2} \mathrm{O}_{5}$ reacts with water traces (present in the organic electrolyte) to form a highly reactive layer of $\mathrm{H}_{3} \mathrm{PO}_{4}$. Once this process is initiated, it will 
generate an electrochemical reduction leading to $\mathrm{P}_{\text {red }}$ and water which will then react further to regenerate $\mathrm{H}_{3} \mathrm{PO}_{4}$. This process will continue until reaching potential below $1 \mathrm{~V}$ where the SEI starts to be formed. The thickness and insulating character of the SEI inhibit $\mathrm{PH}_{3}$ gas release. Combining different surface sensitive techniques lead to understand the changes in the electrode/electrolyte interface during cycling in order to properly engineer and stabilize this interface and prevent gas releases that would raise concerns over battery safety.

\section{Supporting Information}

XPS core levels for C1s and P2p acquired on pristine electrodes cycled with LP30 electrolyte, OEMS data of Pred based electrodes cycled with LP30 electrolyte, SEM images of the pristine and postmortem cycled Pred electrodes, XPS F1s, O1s, C12p core levels acquired on Pred pristine and OCP electrodes, P2p XPS core levels acquired on different pristine sample, P2p XPS core levels acquired on Ppowder -electrode soaked in the electrolyte (LC30), F1s and C12p XPS core levels acquired on Pred electrodes along lithiation, C1s XPS core level acquired on a pristine Ppowder -electrode and a Ppowder -electrode cycled at $1 \mathrm{~V}$. This material is available free of charge via the Internet at http://pubs.acs.org.

\section{Acknowledgment}

We thank the SCCER Heat \& Storage Network (Swiss Competence Center for Heat and Electricity Storage) for financial support. Prof. Dr. Petr Novák is acknowledged for the fruitful discussion on the SEI topic.

\section{References}

1. Nitta, N.; Yushin, G., High-Capacity Anode Materials for Lithium-Ion Batteries: Choice of Elements and Structures for Active Particles. Particle \& Particle Systems Characterization 2014, 31 , (3), 317-336.

2. Yazami, R., Surface chemistry and lithium storage capability of the graphite-lithium electrode. Electrochimica Acta 1999, 45. 
3. Dahbi, M.; Yabuuchi, N.; Fukunishi, M.; Kubota, K.; Chihara, K.; Tokiwa, K.; Yu, X.-f.; Ushiyama, H.; Yamashita, K.; Son, J.-Y.; Cui, Y.-T.; Oji, H.; Komaba, S., Black Phosphorus as a High-Capacity, High-Capability Negative Electrode for Sodium-Ion Batteries: Investigation of the Electrode/Electrolyte Interface. Chemistry of Materials 2016, 28, (6), 1625-1635.

4. Marino, C.; Debenedetti, A.; Fraisse, B.; Favier, F.; Monconduit, L., Activated-phosphorus as new electrode material for Li-ion batteries. Electrochem. Commun. 2011, 13, (4), 346-349.

5. Sun, J.; Lee, H. W.; Pasta, M.; Yuan, H.; Zheng, G.; Sun, Y.; Li, Y.; Cui, Y., A phosphorenegraphene hybrid material as a high-capacity anode for sodium-ion batteries. Nat Nanotechnol 2015, 10, (11), 980-5.

6. Walter, M.; Erni, R.; Kovalenko, M. V., Inexpensive Antimony Nanocrystals and Their Composites with Red Phosphorus as High-Performance Anode Materials for Na-ion Batteries. Sci Rep 2015, 5.

7. Zhang, Y. Y.; Rui, X. H.; Tang, Y. X.; Liu, Y. Q.; Wei, J. Q.; Chen, S.; Leow, W. R.; Li, W. L.; Liu, Y. J.; Deng, J. Y.; Ma, B.; Yan, Q. Y.; Chen, X. D., Wet-Chemical Processing of Phosphorus Composite Nanosheets for High-Rate and High-Capacity Lithium-Ion Batteries. Adv. Energy Mater. 2016, 6, (10).

8. Ramireddy, T.; Xing, T.; Rahman, M. M.; Chen, Y.; Dutercq, Q.; Gunzelmann, D.; Glushenkov, A. M., Phosphorus-carbon nanocomposite anodes for lithium-ion and sodium-ion batteries. J. Mater. Chem. A 2015, 3, (10), 5572-5584.

9. $\quad$ Nitta, N.; Lei, D. N.; Jung, H. R.; Gordon, D.; Zhao, E. B.; Gresham, G.; Cai, J.; Luzinov, I.; Yushin, G., Influence of Binders, Carbons, and Solvents on the Stability of Phosphorus Anodes for Li-ion Batteries. ACS Appl. Mater. Interfaces 2016, 8, (39), 25991-26001.

10. Qian, J. F.; Qiao, D.; Ai, X. P.; Cao, Y. L.; Yang, H. X., Reversible 3-Li storage reactions of amorphous phosphorus as high capacity and cycling-stable anodes for Li-ion batteries. Chem. Commun. 2012, 48, (71), 8931-8933.

11. Sun, L. Q.; Li, M. J.; Sun, K.; Yu, S. H.; Wang, R. S.; Xie, H. M., Electrochemical Activity of Black Phosphorus as an Anode Material for Lithium-Ion Batteries. J. Phys. Chem. C 2012, 116, (28), 14772-14779.

12. LJ., W.-R., Three fatalities involving phosphine gas, produced as a result of methamphetamine manufacturing. J Forensic Sci. 1999, 44, (3), 647-652.

13. Rüdiger Walz, A. B., Chemical Behaviour of Red Phosphorus in Water. Clariant report 2000.

14. B. Pepelko, J. S., P. R. Harp, J. H. Kim, D. Gray and E. L. Anderson, Worker exposure standard for Phosphine gas. Risk Analysis 2004, 24, (5), 1201-1213.

15. E. J. Berg, P. Novák, ECL annual Report, Paul Scherrer Institut 2012.

16. Analytical, H. Relative sensitivity - RS measurements of Gases. https://www.hidenanalytical.de/wp-content/uploads/pdf/RS_Measurement_of_Gases_Hiden_Analytical_App_Note_282.pdf

17. $\bar{Z}$ Zhou, F.; Cococcioni, M.; Marianetti, C. A.; Morgan, D.; Ceder, G., First-principles prediction of redox potentials in transition-metal compounds with $\$ \backslash$ mathrm $\{$ LDA $\}+$ U\$. Phys. Rev. B 2004, 70, (23), 235121.

18. Jain, A.; Hautier, G.; Ong, S. P.; Moore, C. J.; Fischer, C. C.; Persson, K. A.; Ceder, G., Formation enthalpies by mixing GGA and GGA calculations. Phys. Rev. B 2011, 84, (4), 045115.

19. Streich, D.; Gueguen, A.; Mendez, M.; Chesneau, F.; Novak, P.; Berg, E. J., Online Electrochemical Mass Spectrometry of High Energy Lithium Nickel Cobalt Manganese Oxide/Graphite Half- and Full-Cells with Ethylene Carbonate and Fluoroethylene Carbonate Based Electrolytes. J. Electrochem. Soc. 2016, 163, (6), A964-A970.

20. Aurbach, A. S. a. D., X-ray Photoelectron Spectroscopy Study of Surface Films Formed on Li Electrodes Freshly Prepared in Alkyl Carbonate Solutions. Langmuir 1999, 15.

21. Bodenes, L.; Darwiche, A.; Monconduit, L.; Martinez, H., The Interphase a key parameter of the high performance of $\mathrm{Sb}$ in sodium-ion batteries: Comparative X-ray Photoelectron Spectroscopy study of Sb/Na-ion and Sb/Li-ion batteries. Journal of Power Sources 2015, 273, 14-24. 
22. Gieu, J. B.; Courreges, C.; El Ouatani, L.; Tessier, C.; Martinez, H., Temperature effects on $\mathrm{Li}_{4} \mathrm{Ti}_{5} \mathrm{O}_{12}$ electrode/electrolyte interfaces at the first cycle: A X-ray Photoelectron Spectroscopy and Scanning Auger Microscopy study. J. Power Sources 2016, 318, 291-301.

23. Ansari, S. A.; Ansari, M. O.; Cho, M. H., Facile and Scale Up Synthesis of Red PhosphorusGraphitic Carbon Nitride Heterostructures for Energy and Environment Applications. Sci Rep 2016, 6, 27713.

24. F. Claeyssens, G. M. F., N. L. Allan, P. W. May and M. N. R. Ashfold, Phosphorus carbides: theory and experiment. Dalton Transaction 2004.

25. Edmonds, M. T.; Tadich, A.; Carvalho, A.; Ziletti, A.; O'Donnell, K. M.; Koenig, S. P.; Coker, D. F.; Ozyilmaz, B.; Neto, A. H.; Fuhrer, M. S., Creating a Stable Oxide at the Surface of Black Phosphorus. ACS Appl Mater Interfaces 2015, 7, (27), 14557-62.

26. Yi, H.; Yu, Q.; Tang, X.; Ning, P.; Yang, L.; Ye, Z.; Song, J., Phosphine Adsorption Removal from Yellow Phosphorus Tail Gas over $\mathrm{CuO}-\mathrm{ZnO}-\mathrm{La}_{2} \mathrm{O}_{3} /$ Activated Carbon. Industrial \& Engineering Chemistry Research 2011, 50, (7), 3960-3965.

27. E. Horowitz, J. E. P., Characterization and Performance of Calcium Phosphate Coatings for Implants, Numéro 1196. 1994.

28. Rhodium, Regenerative role of the red phosphorus in the couple HI(aq)/P(red). J. Organomet. Chem. 1997, 529, 295-299.

29. Baris, W. M. V. a. J. M., Changes in the Surface of Platinum in Hot Concentrated Phosphorx Acid at Low Potentials. Electrochimica Acta 1977, 23, 463-466.

30. Philippe, B.; Dedryvère, R.; Allouche, J.; Lindgren, F.; Gorgoi, M.; Rensmo, H.; Gonbeau, D.; Edström, K., Nanosilicon Electrodes for Lithium-Ion Batteries: Interfacial Mechanisms Studied by Hard and Soft X-ray Photoelectron Spectroscopy. Chemistry of Materials 2012, 24, (6), 11071115.

31. Ferraresi, G.; Czornomaz, L.; Villevieille, C.; Novak, P.; El Kazzi, M., Elucidating the Surface Reactions of an Amorphous Si Thin Film as a Model Electrode for Li-Ion Batteries. ACS Appl Mater Interfaces 2016, 8, (43), 29791-29798.

32. Hillman, C., Red Phosphorus Induced Failures in Encapsulated Circuits. In DFR-solutions.

33. Brigham, R. J. Corrosive Effects of Phosphine, Carbon Dioxide, Heat and Humidity on Electronic Equipment: Phase II; 1999.

34. Corbridge, D., Phosphorus: Chemistry, Biochemistry and Technology (6th edition). CRC Press website: 2012. 
Lithium ion battery, phosphorus electrode, phosphine, solid electrolyte interphase, reaction mechanism

C. Marino*, M. El Kazzi, E. J. Berg, M. He, and C. Villevieille*

Interface and Safety Properties of Phosphorus-based Negative Electrodes in Li-ion Batteries

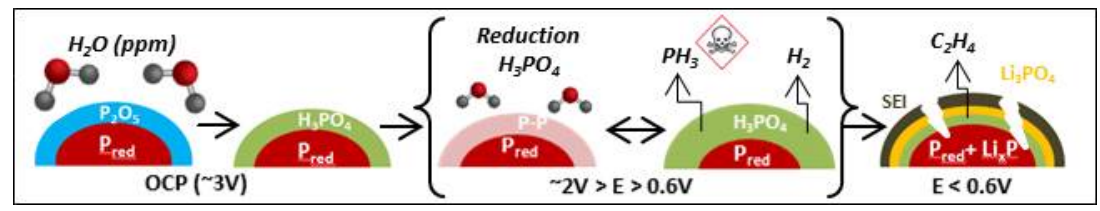

